\title{
Analisis semiotik Charles Sanders Pierce mengenai logo baru Perpustakaan Nasional Republik Indonesia
}

\author{
Rully Khairul Anwar1, Irene Alifa Hapsari², Dian Sinaga ${ }^{3}$ \\ 1,2,3Program Studi Ilmu Perpustakaan, Universitas Padjadjaran \\ Jl. Raya Bandung-Sumedang Km. 21, Jatinangor, Sumedang, Jawa Barat 45363 \\ E-mail: 1rully.khairul@unpad.ac.id, ${ }^{2}$ irenealifa@yahoo.co.id, ${ }^{3}$ dian.sinaga@unpad.ac.id
}

Received: February 2018; Accepted: December 2018; Published: December 2018

\begin{abstract}
The logo is an identity of the institution that to represent the history and the culture and as a promotion media to introducing the institution to the public. The Indonesian National Library has made new logo as a representation this library. This study aimed to find out the meaning of the Indonesian National Library the new logo by determining the symbols, meaning of the symbols, and meaning of the construction of the logo of the Indonesian National Library as the identity of the institution that emphasizes public service. This study used Charles Sanders Pierce's semiotic analysis method through the qualitative approach. Data collection techniques used in this study were observation and literature study. The results showed that the logo of the Indonesian National Library comprised symbols which symbolized star's as natural light and the open books as library wealth. The second this symbols which symbolized the library as a life-long learning; books were the windows of the world, the light in educating the nation, the depth of knowledge, a progressive and advanced institution, an opening of mind and knowledge. Symbols that showed the meaning of the Indonesian National Library identity were graphic elements of books, stars, green, blue, and black colors. Symbols that did not describe a character were the graduations. In conclusion, the meaning of each sign is built into a single meaning that the Indonesian National Library as an institution which always prioritizes public service with graphic elements of open books and the Indonesian National Library new logo.
\end{abstract}

Keywords: Logo; Library; Indonesian semiotics; Charles Sanders Pierce

\begin{abstract}
Abstrak
Logo merupakan identitas suatu lembaga yang merepresentasikan sejarah dan budaya lembaga tersebut, sebagai media promosi dalam memperkenalkan lembaga pada publik. Perpustakaan Nasional Republik Indonesia, telah membuat logo yang baru sebagai bentuk representasi perpustakaan. Penelitian ini bertujuan untuk mengetahui makna logo baru Perpustakaan Nasional Republik Indonesia, dari simbol, makna simbol, dan makna konstruksi logo yang mencerminkan visi perpustakaan untuk memberikan pelayanan kepada masyarakat. Metode yang digunakan dalam penelitian ini adalah analisis semiotika Charles Sanders Pierce melalui pendekatan kualitatif. Teknik pengumpulan data yang digunakan dalam penelitian ini adalah observasi dan studi literatur. Hasil penelitian menunjukkan bahwa logo Perpustakaan Nasional Indonesia memiliki simbol bintang sebagai cahaya alam, dan buku yang terbuka sebagai kekayaan perpustakaan. Kedua simbol ini memiliki makna bahwa perpustakaan merupakan pembelajaran seumur hidup, buku menjadi jendela dunia, cahaya dalam mendidik bangsa, kedalaman pengetahuan, lembaga yang progresif dan maju, sebuah pembukaan pikiran dan pengetahuan. Simbol yang menunjukkan makna identitas Perpustakaan Nasional Indonesia adalah unsur grafis buku, bintang, warna hijau, biru, dan hitam. Simbol yang tidak menggambarkan identitas adalah unsur gradasi. Simpulan penelitian ini, makna masing-masing tanda dibangun menjadi makna tunggal bahwa Perpustakaan Nasional Indonesia sebagai lembaga yang selalu mengedepankan pelayanan publik dengan elemen grafis buku terbuka dan logo transformasi Perpustakaan Nasional Indonesia.
\end{abstract}

Kata kunci: Logo, Perpustakaan; Semiotika Indonesia; Charles Sanders Pierce 


\section{PENDAHULUAN}

Logo adalah salah satu elemen visual yang mewakili suatu perusahaan, organisasi, produk, komunitas, lembaga atau yang lainnya yang memiliki arti atau filosofi yang bersumber dari identitas dan kebudayaan suatu lembaga tersebut. Logo berfungsi untuk membedakan suatu organisasi atau lembaga atau entitasnya dengan entitas lain. Maka sudah menjadi keharusan, bentuk sebuah logo diciptakan unik agar menjadi pembeda dengan entitas-entitas lain.

Selame (1988) dalam Cowin and Matusitz (2011) menyatakan bahwa,

"Logos are symbols that distinguish one model or brand from another. They function to evoke a certain brand in the consumer's mind, and are generally clearly recognizable. Instead of looking for brand names, consumers are accustomed to, and look for, corporate logos as visual shortcuts".

Logo adalah simbol satu obyek untuk memperkenalkannya pada khalayak. Logo berfungsi untuk mendorong khalayak tertarik pada obyek tersebut, dilihat dari nama dan visual atau gambar yang dirancang sedemikian rupa.

Dalam kata lain, logo merepresentasikan ide dan nilai literasi informasi tanpa kata. Logo digunakan sebagai media branding atau promosi, mudah digunakan dan disebarluaskan yang tentunya sesuai kebutuhan konsumen. Identitas tergambar dari sebuah logo karena logo bisa menjadi refleksi diri atau cerminan diri suatu lembaga atau perusahaan. Maka, persepsi orang terhadap suatu lembaga sangat berpengaruh dari bentuk logonya. Selain mewakili identitas, logo pun mewakili tujuan atau visi serta misi lembaga dalam periode berlakunya logo tersebut. dalam beberapa perusahaan-perusahaan tertentu, logo juga berfungsi sebagai pedoman bagi seluruh

karyawannya

dalam melaksanakan tugas yang diembannya agar tetap dalam jalur dalam mewujudkan visi misi yang dimiliki perusahaan tersebut.

Dalam perkembangan era digital, masyarakat dituntut untuk mengikut perkembangan jaman karena ada pepatah mengatakan bahwa, bertahan itu bukanlah untuk mereka yang terkuat, melainkan untuk mereka yang bisa beradaptasi dengan lingkungannya. Dalam proses adapatasi itu diperlukan adanya pembaharuan yang menuntut suatu lembaga agar bisa mengikuti perkembangan jaman. Agar lembaga tersebut tak lekang oleh waktu dan bisa tetap eksis di masyarakat kapan pun itu.

Salah satu caranya ialah merubah identitas visual atau logo. Biasanya perubahan logo ini berawal dari perubahan internal dulu, seperti visi \& misi baru, perubahan paradigma baru, peningkatan kualitas pelayanan, dan lainlain. Segala perubahan itu hendaknya diketahui oleh masyarakat luas untuk meningkatkan reputasi dan citra perusahaan yang mewakili kondisi perusahaan pada saat itu.

Perpustakaan Nasional Republik Indonesia (Perpusnas), "sebagai suatu lembaga pemerintah yang memiliki peran dalam penyediaan dan penyebaran informasi dengan jangkauan pelayanan dan pemustaka yang lebih umum dan luas" (Nurmalia, Kustiyo, \& SulistyoBasuki, 2016). Pada 1 Januari 2015 Kepala Perpusnas, Sri Sularsih secara resmi memperkenalkan tampilan logo baru Perpusnas dari hasil sayembara desain logo Perpusnas. Terdapat perubahan yang terjadi pada logo yaitu pergantian bentuk nyala obor menjadi bentuk bintang.

Berikut gambaran logo dan filosofi logo Perpusnas yang terdahulu. 


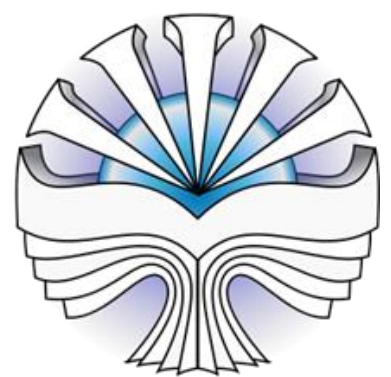

Gambar 1. Logo Lama Perpusnas

Sumber: Perpustakaan Nasional Republik Indonesia, 2014

Berdasarkan Perpustakaan Nasional Republik Indonesia (2014), “Logo Perpustakaan Nasional sebelumnya berbentuk buku dengan nyala obor dengan dua tangan yang terkatup lengkap dengan lima jari yang menopang. Logo tersebut dimaknai bahwa Perpustakaan adalah lambang ilmu pengetahuan yang senantiasa berkembang sebagai usaha mencerdaskan bangsa". Tentunya, logo yang dibuat menyesuaikan misi perpustakaan dalam meningkatkan pendidikan, khususnya minat baca masyarakat.

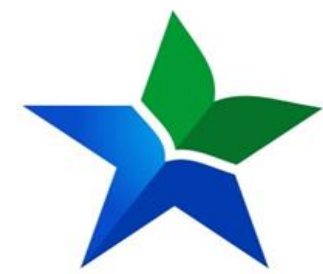

\section{PERPUSTAKAAN NASIONAL} REPUBLIK INDONESIA

Gambar 2. Logo Baru Perpusnas

Sumber: Perpustakaan Nasional Republik Indonesia, 2014

Pada logo Perpusnas yang baru terdapat bentuk yang menyerupai bintang. Apabila dilihat secara seksama terdapat bentuk perpaduan buku terbuka dan bintang dengan kombinasi warna hijau dan biru. Selain itu juga terdapat gradasi pada warna hijau dan biru. Hal tersebut bisa dimaknai bahwa ilmu pengetahuan senantiasa berkembang dan membawa manfaat bagi kesejahteraan umat manusia. Layaknya bintang, perpustakaan adalah lambang ketinggian ilmu dan kemuliaan yang diharapkan mampu membuka cakrawala berpikir umat manusia. Manusia selalu tumbuh dan melakukan regenerasi, begitu juga dengan ilmu pengetahuan yang selalu tumbuh berkembang sesuai dengan jamannya.

Perubahan ini menunjukan bahwa perpusnas merupakan lembaga yang progresif dan selalu berpikiran maju. Itulah alasan mengapa perpusnas mengalami perubahan logo, karena perpustakaan nasional merupakan suatu lembaga yang berkembang, sesuai peradaban umat manusia. Dan juga logo lama sudah dirasa tidak aktual lagi, sehingga diharapkan dengan adanya kehadiran logo baru ini akan membawa harapan baru, semangat baru, dan optimisme baru. Selain itu, karena perubahan di Renstra (rencana strategis) Perpusnas yang harus diubah pada 2015 sampai dengan 2019, maka kebutuhan organisasi juga harus mengganti logo lama menjadi logo baru. Dengan semua kebaruan itu tentunya potensi sumber daya manusianya pun harus dimaksimalkan. Perubahan tersebut semata-mata diciptakan sebagai suatu bentuk pelayananan secara maksimal kepada para masyarakat, khusunya para pengguna Perpustakaan Nasional (Perpustakaan Nasional R.I., 2017).

Rahadian, Rohanda, dan Anwar (2014) menyatakan, "Secara umum tujuan perpustakaan adalah menyediakan informasi yang diperlukan oleh pengguna perpustakaan dan membuat informasiinformasi yang tersedia tersebut dapat diketahui dan diakses oleh masyarakat". Dengan cara memberikan pelayanan terbaik bagi penggunanya tentunya tujuan perpustakaan tersebut akan terlaksana. Cara pelayanan dalam perpustakaan yang lain yaitu dengan adanya public relation in library. Perkembangan Public Relations (PR) 
semakin hari semakin banyak dibutuhkan oleh organisasi.

Suatu lembaga perlu melakukan PR, untuk mengenalkan lembaga tersebut pada masyarakat. Misalnya di bidang media televisi, banyak sekali program televisi yang belum dikenal masyarakat. Maka, melalui penggunaan logo akan menarik penonton untuk menonton program televisi tersebut (Aslinger, 2009).

Pengenalan logo bagi program televisi melalui PR, ternyata efektif membantu dunia massa untuk menambah penonton televisi. Hal ini, dapat dilakukan di perpustakaan juga untuk mengenalkan program perpustakaan kepada pemustaka. Germain (2008) menjelaskan, "So how would you define your library's image? This is an important question in the branding process. In the information world, it is easy to think of companies that have successfully branded their product(s)". Pemustaka harus mengetahui image perpustakaan. Ini dapat dilakukan melalui branding, sebagai bagian dari PR.

Komariah (2008) menambahkan bahwa, "Melalui kegiatan public relations, diharapkan suatu perpustakaan dapat membangun citra yang baik di mata publiknya, untuk selanjutnya akan memperoleh perhatian, pengertian, dukungan, kepercayaan serta penghargaan". Salah satu alat pembentuk citra tersebut adalah identitas korporat. Logo adalah salah satu bagian dari identitas korporat tersebut.

Logo bukan hal yang baru yang ada pada saat ini, tetapi sudah ada pada masa lalu. Martadi (2002) mengatakan bahwa, "Logo pada saat ini yang menjadi bagian dari identitas yang melekat pada perusahaan yang merupakan cerminan dari visi, misi dan ideal suatu perusahaan yang divisualisasikan ke dalam logo perusahaan".

Ini dapat disebut sebagai, "The corporate logo" (Foroudi, Melewar, \&
Gupta, 2017). Logo dari lembaga tertentu menampilkan gambaran dari identitas lembaga tersebut. Desain logo di Perpusnas diciptakan berdasarkan nilainilai, prinsip, kepribadian, sejarah, strategi, struktur, dan rencana program lainnya.

Dalam penelitian Gray and Meyers (2013), merancang rencana strategic selama lima tahun di Russell Library, Middletown. Perpustakaan umum ini belum banyak digunakan oleh masyarakat sekitar, maka dirancang program yang dimulai dari koleksi, staf dan pemustakanya. Untuk menarik ketiga hal ini pada masyarakat, maka perpustakaan menciptakan logo sebagai representasi perpustakaan tersebut.

Untuk mengetahui makna dari logo, maka dilakukanlah kajian semiotik. Thellefsen and Sørensen (2009) dalam Danesi (2013), menjelaskan bahwa melalui semiotik, "Analyzing the techniques that marketers use to semiotize a product into a brand, such as devising a name and a logo for it". Semiotik menjadi teknik untuk menganalisis suatu produk dalam brand, misalnya logo.

Maka, untuk mengetahui simbol, makna simbol, dan makna konstruksi logo Perpusnas, digunakanlah analisis semiotik Charles Sanders Pierce. Berdasarkan hal ini, Peneliti dapat mengetahui makna simbol dari logo perpustakaan dan kesesuaian dengan identitas perpustakaan.

\section{METODE PENELITIAN}

Analisis semiotik pada logo Perpusnas menggunakan pendekatan kualitatif. Moleong (2000) dalam Pinasang (2015) menjelaskan bahwa pendekatan kualitatif ialah, "Prosedur meneliti yang menghasilkan data deskriptif berupa katakata tertulis atau lisan dari orang-orang dan perilaku yang dapat diamati". Peneliti melalui pendekatan kualitatif, berusaha 
menggambarkan fenomena yang sedang diamati lalu dianalisis.

Fenomena yang dianalisis ialah logo Perpusnas dengan tujuan untuk mengetahui makna apa yang terkandung dalam logo tersebut. Sugiyono (2009) dalam Falah (2017) mengatakan, “[...] obyek/subyek penelitian yang dipilih memiliki kualitas dan karakteristik tertentu yang ditetapkan oleh peneliti untuk dipelajari lalu ditarik kesimpulan".

Maka, untuk menganalisis obyek/subyek penelitian digunakanlah teori semiotika Charles Sander Pierce. Pindell (1990) dalam Wood (2017) mengatakan bahwa teori Charles Sander Pierce, "Pragmatic form of semiotic theory for my design research, as Pragmatism is a philosophy that historically has influenced visual communication design". Teori ini menggali makna yang melihat sejarah dan filsafat dari pencipta simbol tersebut, yang didalamnya terdapat desain komunikasi visual.

Setiawan (2015) menambahkan, bahwa dalam menangkap makna dari obyek penelitian diantaranya melihat, "Tanda ikon, indeks, dan simbol". Semiotik digunakan untuk mengungkap makna dari tanda obyek yang sedang dianalisis. Makna tersebut dicari untuk melihat bagaimana latar belakang pencipta obyek menciptakan obyek tersebut. Hal ini berhubungan dengan konsep yang muncul pada obyek terserbut.

Patriansyah (2014) memberikan batasan dari, "Representamen (qualisign, sinsign dan legisign), yang dilakukan untuk menghindari kesalahpahaman [...]". Malah, Wibowo (2011) dalam Usman (2017) menyatakan teori semiotika Charles Sanders Pierce, "Gagasannya bersifat menyeluruh, deskripsi struktural dari semua penandaan, Pierce ingin mengidentifikasi partikel dasar dari tanda dan menggabungkan kembali komponen dalam struktural tunggal". Teori ini melihat penanda dalam obyek yang diteliti. terlebih dahulu penjelasan dibahas tiap konsep, lalu pada akhirnya digabungkan untuk menjadi makna yang utuh.

Dalam penelitian makna logo baru Perpusnas ini, peneliti ikut ke dalam aktivitas Perpusnas sehari-hari, baik dalam rapat internal, kegiatan atau event yang diselenggarakan, hingga ke dalam proses distribusi serah terima buku-buku yang ada di Perpusnas. Berdasarkan hal ini, maka akan diperoleh data mengenai trikotomi Charles Sanders Peirce, yakni tanda, objek dan interpreten.

\section{HASIL DAN PEMBAHASAN}

Perpusnas yang berdiri pada pertengahan tahun 1980, telah mengubah logo perpustakaan pertama kali pada tahun 2015. Zaman yang terus berkembang senantiasa menuntut sebuah lembaga untuk menyesuaikan situasi dan keadaan pada masa itu. Begitu pula dengan logo Perpusnas., setelah lebih dari 30 tahun lamanya, Perpusnas. akhirnya merubah logo mereka. Perubahan logo ini menandakan dibangunnya proses tranformasi lembaga yang cukup signifikan. Beebe (2004) dalam Johannessen (2016) mengatakan,

"Logos are an extremely important species of discourse in processes of globalization and in the post-industrial social order. So important, in fact, that an entire legal discipline, trademark law, is devoted to its regulation. Some describe the function of logos as a way of organizing the economic system and promoting economic efficiency in society in general".

Logo merupakan proses yang penting pada sebuah lembaga. Di dalamnya 
melekat aturan secara hukum dan sebagian logo menggambarkan sistem organisasi dan sistem ekonomi lembaga tersebut. Begitupun logo Perpusnas juga mengisyaratkan visi dan misi lembaga yang baru. Perubahan dilakukan tidak hanya pada logo saja namun pada wilayah internalnya juga. Perpusnas ingin menunjukan visi dan misi mereka dengan paradigma yang baru, bagaimana Perpusnas bisa mendekatkan diri kepada masyarakat dan bisa memberikan motivasi kepada masyarakat.

Sebelum tahapan perubahan logo, tentunya Perpusnas. telah merencanakan dan melaksanakan perubahan dalam segi kualitas pelayanan kepada masyarakat. Segala konsep yang telah dipikirkan oleh pihak Perpusnas., yang akhirnya memunculkan kesepakatan di semua staf dan jajaran Perpusnas. untuk merubah logo menjadi logo yang lebih baru. Logo yang dibuat Didik Hendro Purnomo melalui sayembara dari situs sribu.com ini, akhirnya diresmikan Sri Sularsih, selaku Kepala Perpusnas pada tanggal 1 Januari 2015. Mengenai hal ini sejalan dengan pendapat Kraus and Gierl (2017) yakni,

"Integrative logos are new logos, which are composed of the elements of the original brand logos; the integrative logo is the result of a merger of the elements of the logos of the cooperating brands. Novel logos are entirely new logos, which do not contain any elements of the logos of the cooperating brands".

Logo baru ialah logo yang integrative, di mana masih menyimpan elemen dari logo yang alama atau asli. Selain itu, logo integratif disebut sebagai kerjasama berbagai pihak mempadu padankan nilai logo lama dalam menghasilkan logo baru.

Untuk menjelaskan visualisasi logo Perpusnas, terlebih dahulu memaparkan anatomi logo, klasifikasi logo serta kriteria logo yang baik seperti apa. Payne, Hyman, Niculescu, and Huhmann (2013) memiliki pendapat bahwa desain logo harus memiliki konsep elaborasi, natural, dan harmoni. Ini dapat diamati dari anatomi logo. Berikut anatomi logo Perpusnas.

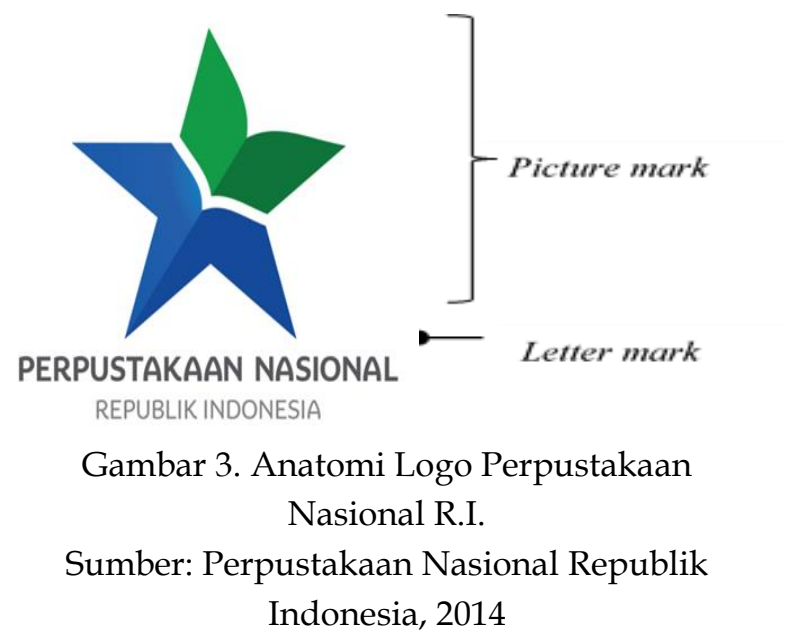

Berdasarkan anatomi logo di atas, dibagi menjadi picture mark dan letter mark. Picture mark ialah berupa gambar atau visual yang akan pertama dilihat oleh pembaca. Lalu letter mark, yakni tulisan sebagai nama dari logo ini. Picture mark dan letter mark, memiliki warna yang senada sebagai warna khas Perpusnas. Maka, warna memang menentukan dalam pembuatan logo.

Logo ini, menggunakan warna biru, hijau dan hitam. Ridgway and Myers (2014) menyatakan bahwa warna biru terkait sifat yang percaya diri, bekerja sama, sukses. Warna hijau sendiri, "[...] also consistent with previous studies and indicate that fashion brands wanting to communicate a commitment to the environment should use a green logo". (Ridgway \& Myers, 2014). Warna hijau sendiri menggambarkan sifat yang konsisten, nyaman, dan mudah menyesuaikan diri sedangkan warna 
hitam menggambarkan sikap tegas. Maka, dari warna yang digunakan dapat menandakan sifat yang dimunculkan dari perpustakaan.

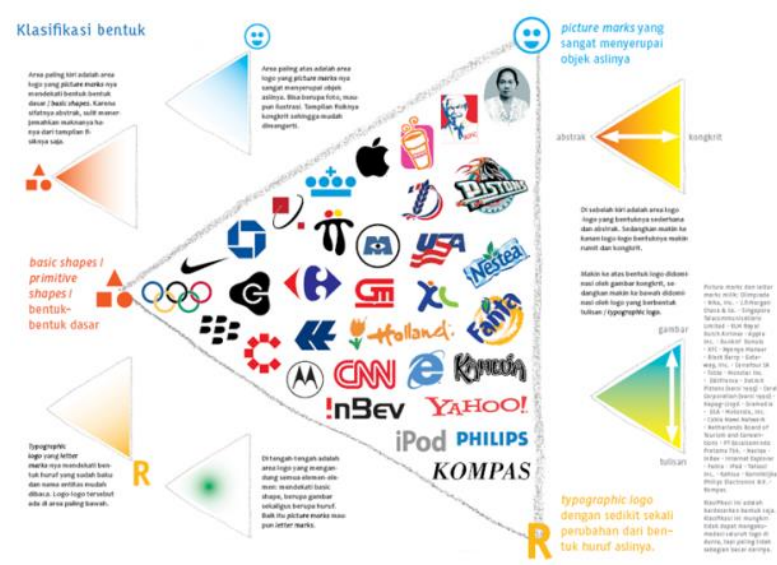

Gambar 4. Klasifikasi bentuk Sumber: Rustan, 2009

Menurut pemaparan klasifikasi bentuk di atas, logo Perpusnas. termasuk dalam bentuk di antara abstrak dan kongkrit. Bila divisualisasikan, akan terlihat seperti ini:

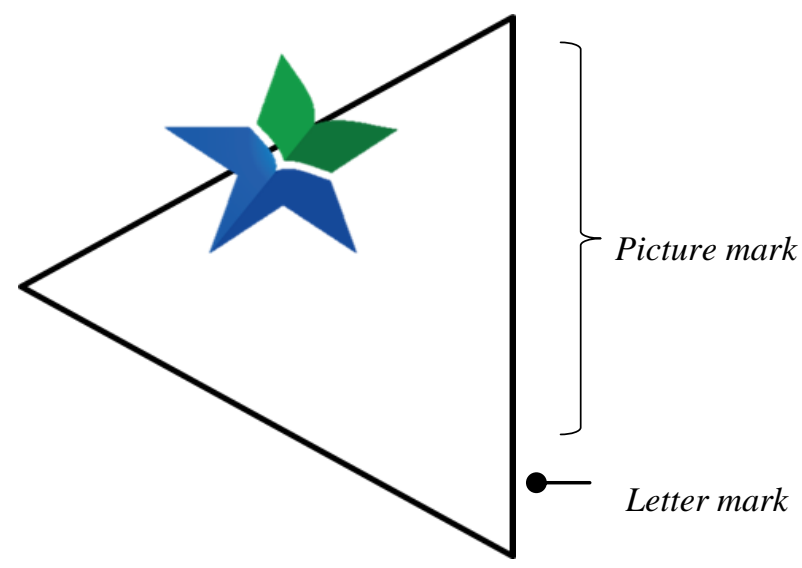

Gambar 3. Klasifikasi bentuk logo Perpusnas hasil modifikasi peneliti Sumber: Hasil Penelitian, 2018

Dalam menciptakan logo, ada beberapa kriteria, diantaranya, "(1) achieve a decent level of recognition and familiarity, (2) activate a consistent and unique set of brand meanings, and (3) evoke positive affect" (Wang, Duff, \& Clayton, 2017). Logo yang dibuat harus mampu menampilkan semangat kebersamaan suatu lembaga, konsisten untuk menampilkan hal unik dan memberikan dampak postif bagi pembaca.

Visi misi Perpusnas terepresentasikan melalui logo baru. Dalam sebuah logo, visi misi, budaya, karakter sebuah perusahaan harus tervisualisasikan. Namun, tidak semua aspek perlu untuk diperlihatkan melalui sebuah logo. Logo hanyalah representasi beberapa karakter yang menjadi ciri khas sebuah lembaga atau perusahaan.

Perubahan logo Perpusnas ini dibuat melalui sayembara melalui situs sribu.com. Adapun design brief dari situs sribu.com yang diberikan oleh pihak Perpusnas. kepada kontestan pembuat logo, yaitu sebagai berikut, 1) desain logo yang Perpusnas inginkan adalah desain yang melambangkan filosofi Perpustakaan yaitu: a) perpustakaan pusat sumber belajar sepanjang hayat; buku jendela dunia, sumber informasi dan ilmu pengetahuan; b) melambangkan pelita dalam mencerdaskan bangsa, c) melambangkan pengetahuan yang selalu dicari dan tidak terbatas ruang dan waktu, 2) desain logo yang Perpusnas. inginkan, memiliki kriteria sebagai berikut: a) sederhana; b) mudah diingat dan berkesan, c) tak lekang oleh waktu, dan 4) bisa diterapkan diberbagai media.

Melalui ketentuan-ketentuan design brief tersebut, bisa disimpulkan bahwa Perpusnas. ingin menonjolkan beberapa karakter dari sekian karakter yang dimiliki Perpusnas. untuk direpresentasikan melalui sebuah logo. Karakter Perpusnas sesuai dengan Undang-Undang Republik Indonesia Nomor 43 Tahun 2007 tentang perpustakaan yang menyatakan bahwa,

\section{"Perpustakaan Nasional adalah} lembaga pemerintah non 
departemen (LPND) yang melaksanakan tugas pemerintahan dalam bidang perpustakaan yang berfungsi sebagai perpustakaan pembina, perpustakaan rujukan, perpustakaan deposit, perpustakaan penelitian, perpustakaan pelestarian, dan pusat jejaring perpustakaan, serta berkedudukan di ibukota negara “ (Kementrian Pendidikan dan Kebudayaan, 2007).

Pusat sumber belajar sepanjang hayat berarti proses pendidikan yang berproses secara terus menerus, bermula sejak seseorang dilahirkan hingga meninggal dunia. Perpusnas. ingin memposisikan dirinya sebagai pusat pembelajaran bagi masyarakat yang tidak terbatas oleh usia. Berbagai rentan usia diharapkan bisa menjadikan Perpusnas. sebagai pusat pembelajaran bagi masyarakat.

Secara visualisasi, belum terdapat grafis atau simbol yang mewakili karakter Perpusnas. sebagai pusat pembelajaran sepanjang hayat. Simbol visual yang mendekati untuk mewakili simbol pembelajaran sepanjang hayat yaitu lingkaran, karena lingkaran menggambarkan sesuatu yang tiada akhir, terus menerus, dan berproses.

Perpusnas memiliki visi “Terwujudnya Indonesia Cerdas Melalui Gemar Membaca dengan Memberdayakan Perpustakaan", melalui buku. Berdasarkan logo baru Perpusnas, sudah terdapat elemen grafis ikon buku terbuka yang mewakili identitas Perpusnas, sebagai lembaga yang mengelola informasi, contohnya buku cetak yang memiliki halaman banyak, dan dibuat seperti terbuka.

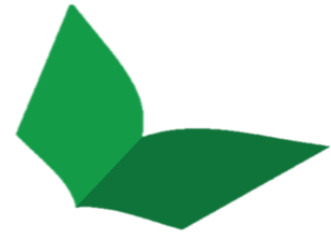

Gambar 4. Elemen grafis buku logo Perpusnas Sumber: Perpustakaan Nasional Republik Indonesia, 2014

Perpusnas merupakan lembaga yang berperan dalam mencerdaskan kehidupan bangsa, membebaskan bangsa dari kebodohan melalui ilmu dan informasi yang dimiliki Perpusnas. Ikon bintang pada logo Perpusnas. sudah tepat dalam merepresentasikan Perpusnas. sebagai lembaga yang berperan sebagai pelita dalam mencerdaskan bangsa. Maka simbol pelita dalam mencerdaskan bangsa sudah terepresentasikan melalui elemen grafis bintang.

Selain itu, makna logo Perpusnas., dapat dianalisis juga pada bentuk bintang. Sebenarnya, manusia telah lama mengamati bintang-bintang di langit malam. Manusia menjadi kagum melihat kebesaran dan misteri yang hadir di seluruh alam semesta ini. Kekaguman itu bisa tercermin dalam upaya mereka menghadirkan berbagai mitos dalam perspektif budaya masing-masing mengenai makna bintang.

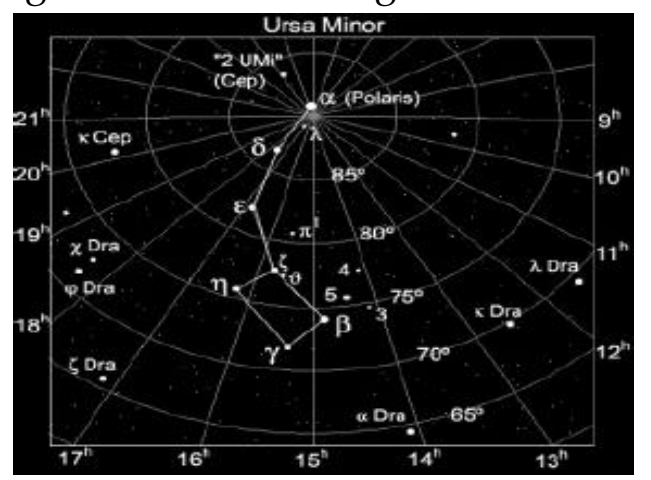

Gambar 5. Ursa Major / Rasi Bintang Biduk Sumber: kafeastronomi.com/mencari-arahdengan-bintang.html 


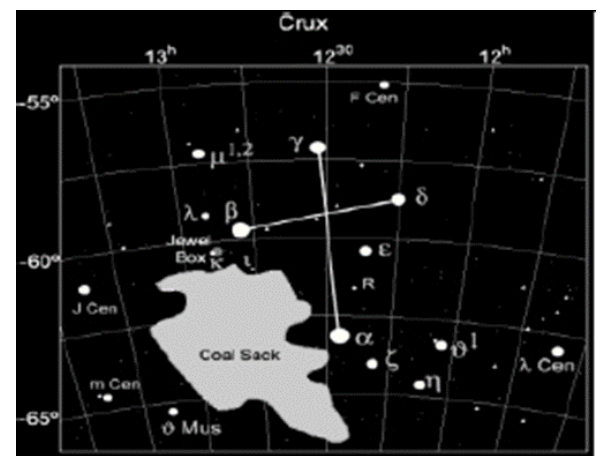

Gambar 6. Crux/ Rasi bintang layang-layang Sumber: kafeastronomi.com/mencari-arahdengan-bintang.html
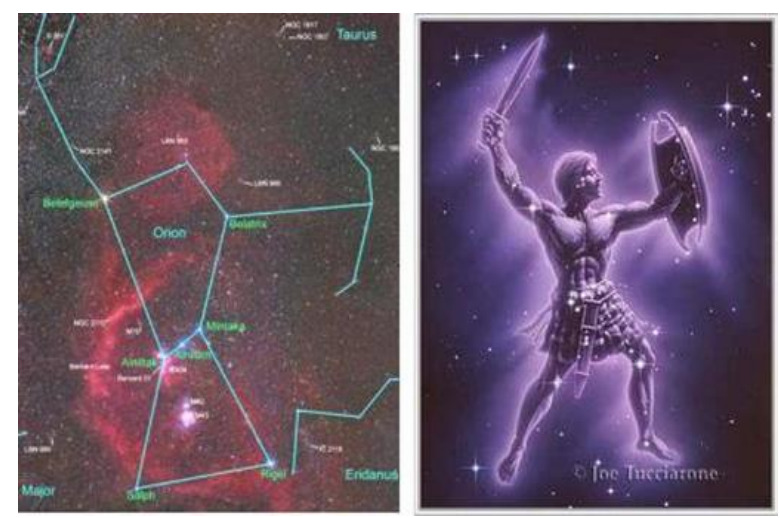

Gambar 7. Rasi bintang pemburu Sumber: kafeastronomi.com/mencari-arahdengan-bintang.html

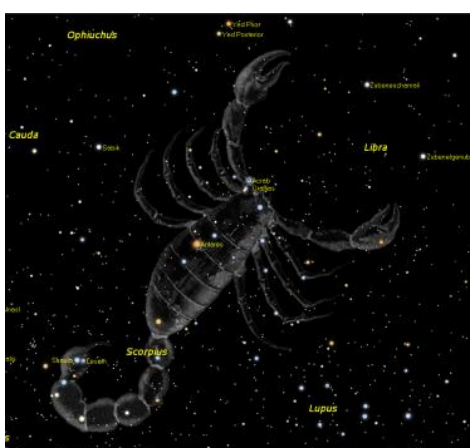

Gambar 8. Rasi Bintang Kalajengking

Sumber: kafeastronomi.com/mencari-arahdengan-bintang.html

Berdasarkan gambar di atas, rasi bintang di atas diantaranya, rasi bintang biduk, rasi bintang layang-layang, rasi bintang pemburu dan rasi bintang kalajengking. Ke-4 rasi bintang ini sering dipergunakan manusia sebagai penanda kegiatan yang akan dilakukannya.

Rasi binatang-bintang ini sering digunakan para petani, nelayan atau masyarakat lainnya sebagai penunjuk waktu dalam dunia pertanian dan perikanan. Tak hanya itu, melalui rasi bintang, manusia akan terbantu untuk mengamati gejala alam yang ada di wilayahnya.

Rasi bintang di atas membentuk suatu konfigurasi khusus untuk alat navigasi bagi para pelaut ketika tidak ada kompas, begitu juga saat kita tersesat di pegunungan sebagai petunjuk arah utara dan selatan.

Elemen grafis bintang menjadi representasi pelita, seperti yang sudah dipaparkan di atas, bintang secara ilmiah dan historis telah menjadi penunjuk arah bagi para pelaut sebelum diciptakannya alat navigasi.

Logo Perpusnas. memiliki biru, hijau, dan hitam. Habsari (2010) menjelaskan bahwa warna biru,

"Yaitu ketenangan, sejuk, kesunyian, kecerdasan, kebenaran, keagungan, diam (tenang), melankolis, tidak liar, ketulusan, kemurahan hati, ketenangan, harapan, kenyamanan, terkontrol, penekanan pada perasaan, konstan, penyelesaian, kesetiaan, intropeksi".

Warna biru pada bintang dalam logo sudah tepat diterapkan pada elemen grafis bintang karena simbolisme warna biru salah satunya merupakan keagungan dan sering diasosiasikan tempat tertinggi karena biru dalam realitasnya adalah warna langit.

Warna biru akan memberi ketenangan sehingga berdampak pada ketenangan berpikir. Hal ini mengingat Perpusnas sendiri mempunyai peran dalam upaya mencerdaskan bangsa. Dengan ketenangan berpikir kita akan mengambil suatu keputusan secara tepat. 
Selain itu, warna biru erat kaitannya dengan warna laut yang melambangkan kedalaman ilmu pengetahuan yang dimiliki oleh Perpusnas.

Lalu simbolis lainnya ialah warna hijau, dedaunan dan hutan karena warna ini banyak terdapat di alam. Makna secara psikologis warna hijau adalah, "Pertumbuhan, pembaharuan, keseimbangan, harmoni, dan lingkungan (Rastati, 2008).

Menurut para narasumber,

"Ketika dilihat dari segi semiotika sosial, warna akan dimaknai berbeda ketika berada dilingkungan budaya berbeda pula. Misalnya, warna merah itu berani. Ketika di budaya Chinese warna merah itu bermakna kesenangan. Ketika ada salah satu dari orangtua mereka meninggal, orang chinese tidak diperkenankan memakai pakaian berwarna merah untuk beberapa kurun waktu. Karena akan dianggapnya sebagai kesenangan diatas meninggalnya orangtua mereka. Pada logo Perpusnas ini parameter yang digunakan bukan berdasarkan etnik ataupun budaya, namun bagaimana warna tersebut dilihat sebagai makna simbolis, yaitu makna warna berdasarkan kemiripan warna dengan alam" (Mutiaz, I. R., wawancara, December 1, 2018).

Selain itu, warna hijau apabila diasosiasikan dengan alam maka warna hijau dikaitkan dengan dedaunan atau sesuatu yang terdapat di alam yang senantiasa tumbuh. Tidak bisa kita pungkiri bahwa di dunia ini ilmu pengetahuan akan selalu berkembang dan bertambah setiap detiknya. Maka penggunaan warna hijau akan sangat sesuai sebagai pertumbuhan ilmu pengetahuan yang ada di dunia ini. Kemudian dalam logo Perpusnas., warna hijau ini diterapkan pada elemen grafis buku yang terbuka, terbuka berarti buku tersebut kita baca. Pengertian membaca sendiri yaitu melihat serta memahami isi dari apa yang tertulis. Maka diharapkan dengan membaca buku kita akan terus merasa nyaman melihat apa yang kita baca.

Penggunaan elemen warna hijau pada elemen grafis buku sudah tepat, karena warna hijau sering dimaknai warna kecerdasan tinggi. Kecerdasan tentunya diperoleh melalui ilmu pengetahuan yang senantiasa bertambah setiap harinya. Sumber ilmu pengetahuan yang berasal dari pustaka yang dimiliki oleh Perpusnas. Terakhir ialah penggunaan warna hitam pada huruf, berfungsi untuk memberikan ketegasan dan kekuatan yang terkandung dalam logo Perpusnas.

Melalui perubahan logonya, Perpusnas. ingin menunjukan identitas lembaga yang selalu berpikiran maju dan modern melalui font yang digunakan dalam logo Perpusnas bernama "Ringo". Jenis font Ringo ini yaitu sans serif. San serif (yang artinya: tanpa serif). Serif adalah semacam tambahan khusus yang berbentuk kait pada terminal. Serif diidentikan dengan huruf kuno karena banyak ahli yang memperkirakan sejarah bentuk serif berasal dari zaman Romawi. Typeface serif ini pun muncul lebih dulu dibanding sanserif. Serif baru muncul pada abad 18. Banyak kelebihan dan kekurangan masing-masing antar jenis huruf serif dan san serif. Namun, dalam hal fleksibelitas dan ketahanan, sans serif lebih unggul karena serif dianggap kuno untuk 
dijadikan suatu identitas perusahaan yang ingin mengikuti perkembangan zaman.
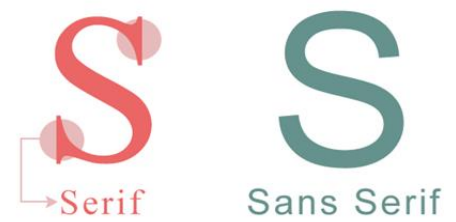

Gambar 10. Perbedaan Serif dan Sans Serif

PERPUSTAKAAN NASIONAL REPUBLIK INDONESIA

Gambar 11. Huruf pada logo

Sumber: Perpustakaan Nasional Republik Indonesia, 2014

Dalam logo Perpusnas, tulisan "PERPUSTAKAAN NASIONAL" berfungsi sebagai penekanan nama lembaga negara, sehingga typeface dicetak tebal dan lebih besar sedangkan "REPUBLIK INDONESIA" hanya sebagai penjelas dan pemberi keterangan pada nama lembaga negara tersebut sehingga typeface dicetak lebih kecil. Sesuai dengan tujuan Perpusnas. yang ingin menghapuskan kesan kaku dan ortodoks mengenai perpustakaan itu sendiri, maka konsep font yang digunakan yaitu font yang berkarakter simpel/sederhana.

Henderson, Giese, and Cote (2004) dalam Wang, Duff, and Clayton (2017) menyatakan bahwa desain typeface mempengaruhi karakteristik logo. Dalam tipografi berkaitan erat dengan rancangan huruf dan pencetakannya.

Pemilihan atau penciptaan jenis huruf perusahaan tidak berdasarkan selera/kesukaan semata. Masing-masing jenis huruf, seperti elemen identitas lainnya, membawa sifat/kepribadiannya sendiri-sendiri. Maka dibutuhkan pemilihan yang sesuai agar tipografi dapat mereperesentasikan identitas lembaga.
Huruf yang sudah didesain dengan perhitungan yang sangat akurat dan dibentuk dengan sangat indah belum tentu menjamin efektifitasnya sebagai penyampai pesan. Oleh karena itu, faktor huruf menjadi faktor penentu akan segalanya. Bisa disimpulkan, elemen tipografi dalam logo Perpusnas. sudah memenuhi kriteria legibility dan reability karena masing-masing karakter huruf pada font 'Ringo' ini cukup terlihat perbedaannya sehingga mudah untuk dibaca meskipun semua huruf menggunakan huruf cetak. Kemudian, jarak antar karakter huruf tidak terlalu berdempet sehingga font ini masih tergolong pada font yang memenuhi readibility-nya.

Dari sisi elemen warna, Perpusnas. belum menggambarkan karakter lembaga yang progresif dan maju. Warna biru dan hijau termasuk ke dalam warna daerah warna dingin. Warna dingin merupakan warna yang terkesan tenang, pasif, melankoli, sayu, sendu. Maka setidaknya diperlukan warna yang berasal dari daerah warna panas untuk menggambarkan Perpusnas. sebagai lembaga yang progresif dan berpikiran maju. Warna panas memberikan kesan semangat, kuat \& aktif. Namun apabila terlalu didominasi warna panas akan merangsang dan menjerit sihingga terkesan terlalu agresif. Begitu pula dengan warna dingin, dominasi warna dingin akan memberi kesan sedih dan melankoli.

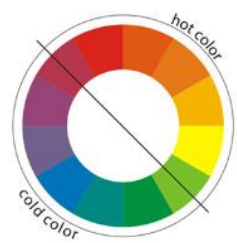

Gambar 12. Color Wheel Sumber: decoart.com 
Pada gradasi logo Perpusnas terlihat perbedaan kontras warna terang yang melingkupi setengah bagian logo ke setengah lagi bagian logo yang gelap. Dalam logo Perpusnas terdapat simbolsimbol yang mempunyai tema utamanya masing-masing. Terkandung simbol grafis, warna, serta teks didalam logo Perpusnas. Setiap simbol yang terkandung di dalamnya diinterpretasi, lalu lahirlah sebuah makna.

Seperti halnya logo Perpusnas., simbol-simbol yang terkandung di dalam logo Perpusnas. juga mengkomunikasikan pesan mengenai identitas Perpusnas. itu sendiri sebagai lembaga yang mengedepankan pelayanan kepada masyarakat. Ini sesuai pendapat Wang et al., 2017), bahwa desain logo harus memiliki tiga konsep visual, diantaranya visual level tinggi, visual level semantik, visual dasar variabel.

Dari ketiga konsep visual tersebut, maka terbentuklah logo yang mencerminkan identitas dari lembaa penciptanya. Lalu untuk mencari dan menemukan makna keseluruhan dari logo Perpusnas, terlihat bahwa pesan lembaga ialah mengedepankan pelayanan kepada masyarakat. Maka, berdasarkan hasil konstruksi simbol-simbol yang telah dibahas sebelumnya. Ide-ide dan maknamakna yang sudah dibahas sebelumnya kemudian dikonstruksi sehingga lahirlah sebuah gagasan baru yang realistis.

Perpusnas merupakan lembaga pemerintah tingkat nasional yang bergerak dibidang informasi. Perpusnas. mengganti logonya pada tanggal 1 Januari 2015. Pergantian logo ini diharapkan akan membawa semangat baru, optimisme baru, serta harapan baru. Selain ingin memberikan efek positif bagi internal Perpusnas. Pihak Perpusnas juga ingin membangun citra positif dibenak masyarakat melalui logo barunya sebagai identitas yang mengedepankan pelayanan kepada masyarakat. Representasi makna tersebut tergambar pada logo Perpusnas yang baru, yaitu pada elemen grafis buku terbuka.

Terbuka menurut Kamus Besar Bahasa Indonesia yaitu, "Tidak terbatas pada orang tertentu saja" (Kementrian Pendidikan dan Kebudayaan, 2016). Maka dari tampilan logo tersebut merepresentasikan pelayanan yang diberikan oleh Perpusnas yang melayani semua lapisan masyarakat tanpa terkecuali.

Sebagus dan sebanyak apapun informasi yang dimiliki, apabila perpustakaan tersebut tidak bisa mendistribusikan informasi kepada seluruh lapisan masyarakat dengan baik maka hal itu akan sia-sia saja. Maka, Perpusnas. secara bertahap meningkatkan kualitas pelayanan perpustakaan dan mendiseminasikan informasi program terbaru ke perpustakaan se-Indonesia.

Perpustakaan harus bekerja sama dan bahu-membahu memberikan pelayanan perpustakaan bagi pemustaka. Ini telah tergambar pada logo terbaru.

Logo Lama Perpusnas Logo Baru Perpusnas

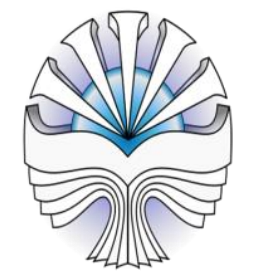

Perpustakaan Nasional RI

$1989-2014$

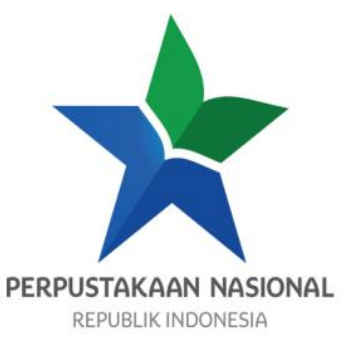

2014 - sekarang
Gambar 13. Perbedaan logo lama dengan logo baru

Sumber: Adaptasi Peneliti, 2018 
Bila dilihat, desain logo Perpusnas terdahulu bersifat detail dibandingkan logo yang baru sedangkan logo yang baru lebih terlihat sederhana. Transformasi dari logo terdahulu menuju logo yang baru yakni lebih sederhana dan mudah dikenali bentuknya karena secara spontan masyarakat akan lebih cepat menangkap bentuk logo Perpusnas. yang baru dibandingkan logo yang lama. Dari wujud transformasi atau perubahan tersebut, menunjukan bahwa desain logo Perpusnas. yang baru merepresentasikan perubahan reformasi birokrasi yang ada di dalam sistem pelayanan Perpusnas itu sendiri. Dari hasil penelitian dan pembahasan di atas, dapat terlihat bahwa logo Perpusnas memiliki makna yang berhubungan dengan identitas lembaga yang mengedepankan pelayanan kepada masyarakat. Apa yang terlihat dalam logo Perpusnas mencerminkan karakteristik lembaga tersebut. Simbol-simbol yang terdapat pada logo Perpusnas. merupakan refleksi dari sebuah lembaga. Simbol yang memuat citra Perpusnas. yang mengkomunikasikan identitasnya kepada khalayak luas. Logo adalah media komunikasi bagi Perpusnas. untuk menyampaikan dan menyebarluaskan identitas tersebut untuk membangun citra lembaga di benak masyarakat. Perpusnas. ingin memperkenalkan jati dirinya sebagai lembaga perpustakaan yang menjadi penunjuk arah bagi masyarakat melalui pendayagunaan perpustakaan itu sendiri. Pada penelitian selanjutnya, bisa dicari pengaruh logo perpustakaan yang baru terhadap pengaplikasian visi dan misi perpustakaan.

\section{SIMPULAN}

Penelitian mengenai analisis semiotik Charles Sanders Pierce pada logo
Perpusnas dapat terlihat dari simbol, makna simbol, dan makna konstruksi logo. Logo Perpusnas., memiliki simbol bintang dan buku terbuka. Simbol bintang layaknya bintang di langit untuk menerangi dunia. Lalu buku terbuka, merupakan salah satu koleksi perpustakaan, yakni buku tercetak yang sedang dibaca pemustaka. Dari kedua simbol ini, memiliki makna yang hampir sama dari konotasi yang berbeda. Bintang untuk menerangi dunia dan buku untuk menerangi pengetahuan manusia. Jadi, kedua simbol memiliki tujuan bahwa perpustakaan sebagai sumber pengetahuan manusia tidak akan redup. Walaupun bintang redup pada pagi dan siang hari, bintang memiliki fungsi membantu manusia sebagai penunjuk arah, Selain itu, kedua simbol ini didukung oleh warna biru, hijau dan hitam. Warna biru memberi arti bahwa perpustakakaan selalu hadir memberikan pelayanan pada pemustaka. Warna hijau menandaka bahwa perpustakaan merupakan tempat yang nyaman untuk belajar, dan warna hitam mencirikan ketegasan. Berdasarkan hal ini, untuk penelitian selanjutnya dapat dianalisis kembali mengenai pengenalan logo Perpusnas. R.I. di masyarakat. Hal ini bisa dianalisis mengenai pengaruh logo Perpusnas. R.I. dalam menarik minat pemustaka untuk menggunakan fasilitas perpustakan.

\section{DAFTAR PUSTAKA}

Aslinger, B. (2009). Creating a network for queer audiences at logo TV. Popular Communication: The International Journal of Media and Culture, 7(2), 107121.

https://doi.org/http://www.tandfo nline.com/action/showCitFormats?d 
oi $=10.1080 / 15405700902776495$

Cowin, E., \& Matusitz, J. (2011). The ongoing transformation of the McDonald's logo: A semiotic perspective. Journal of Visual Literacy, $30(2)$, 20-38. https://doi.org/https:/ / doi.org/10.1 080/23796529.2011.11674688

Danesi, M. (2013). Semiotizing a product into a brand. Social Semiotics, 23(4), 464-476.

https://doi.org/https://doi.org/10.1 080/10350330.2013.799003

Falah, K. H. (2017). Pengembangan bahan ajar matematika berbasis CERGAM berkarakter dengan pendekatan kontekstual pada materi SPLDV untuk Siswa Kelas VII SMP/MTs tahun (Skripsi) pelajaran 2016/2017. Universitas Islan Negeri Walisongo, Semarang. Retrieved from http:/ / eprints.walisongo.ac.id/7859/ 1/Binder1.pdf

Foroudi, P., Melewar, T. C., \& Gupta, S. (2017). Corporate logo: History, definition, and components. International Studies of Management $\mathcal{E}$ Organization, 47(2), 176-196. https://doi.org/https:/ / doi.org/10.1 080/00208825.2017.1256166

Germain, C. A. (2008). A brand new way of looking at library marketing. Public Services Quarterly, 4(1), 73-78. https://doi.org/https://doi.org/10.1 080/15228950802135806

Gray, A. K., \& Meyers, A. (2013). A strategic plan for Russell Library, Middletown, 2013-2017. Public Library Quarterly, 32(4), 322-332. https://doi.org/https://doi.org/10.1 080/01616846.2013.848133

Habsari, S. U. H. (2010). Aplikasi semiotik \& efek psikologis tampilan warna pada rumah minimalis. Jurnal Riptek, $4(1)$, 37-44. Retrieved from http://bappeda.semarangkota.go.id/ $\mathrm{v} 2 / \mathrm{wp}-$ content/uploads/2013/12/5.aplikasisemiotik_Sinung.pdf

Johannessen, C. M. (2016). Experiential meaning potential in the Topaz Energy logo: A framework for graphemic and graphetic analysis of graphic logo design. Social Semiotics, 27(1), $1-20$. https://doi.org/https://doi.org/10.1 080/10350330.2016.1187880

Kementrian Pendidikan dan Kebudayaan. Undang-Undang Republik Indonesia nomor 43 tahun 2007 tentang perpustakaan, Pub. L. No. 43 (2007). Indonesia:

http://www.bpkp.go.id/uu/filedow nload/2/36/176.bpkp. Retrieved from

http://www.bpkp.go.id/uu/filedow nload/2/36/176.bpkp.

Kementrian Pendidikan dan Kebudayaan. (2016). KBBI daring. Retrieved from https://kbbi.kemdikbud.go.id/entri/ terbuka

Komariah, N. (2008). Kegiatan public realtions di perpustakaan perguruan tinggi. In Dialog Interaktif: Penerapan Konsep Public Relations pada Perpustakaan. Riau: UIN SUSKA Riau. Retrieved from http:/ / pustaka.unpad.ac.id/wpcontent/uploads/2010/07/kegiatan_ public_relation_di_perpustakaan.pdf

Kraus, A., \& Gierl, H. (2017). The logo matters: The effect of the logo type on the attitude towards co-products. International Journal of Advertising, 36(5), 743-760. https:/ / doi.org/https:/ / doi.org/10.1 080/02650487.2017.1340926

Martadi. (2002). Reposisi citra melalui logo. Jurnal Nirmana, 4(1), 62-72. 
Retrieved

from

http:/ / nirmana.petra.ac.id/index.ph

p/dkv/article/viewFile/16080/16072

Nurmalia, I., Kustiyo, A., \& Sulstyo-Basuki

(2016). Evaluasi penggunaan layanan

koleksi e-resources menggunakan

standar indikator kinerja (ISO

11620:2014) di Perpustakaan Nasional

RI. Jurnal Pustakawan Indonesia, 15(1-

2), 58-72. Retrieved from http://journal.ipb.ac.id/index.php/j

pi/article/view/16919/12294

Patriansyah, M. (2014). Analisis semiotika

Charles Sanders Peirce karya Patung

Rajudin berjudul manyeso diri. Ekspresi Seni: Jurnal Ilmu Pengetahuan Dan Karya Seni, 16(2), 239-252. Retrieved from https://media.neliti.com/media/pub lications/90085-ID-analisis-semiotikacharles-sanders-peirc.pdf

Payne, C. R., Hyman, M. R., Niculescu, M., \& Huhmann, B. A. (2013). Anthropomorphic responses to newto market logos. Journal of Marketing Management, 29(1-2), 122-140. https:/ / doi.org/https://doi.org/10.1 080/0267257X.2013.770413

Perpustakaan Nasional R.I. (2017). philosophy of logo. Retrieved from https:/ / www.perpusnas.go.id/ falsaf ah.php?lang=en

Perpustakaan Nasional Republik Indonesia. Keputusan Kepala Perpustakaan Nasional Republik Indonesia nomor 115 tahun 2014 tentang penetapan logo perpustakaan nasional, Pub. L. No. 115 (2014). Indonesia. Retrieved from https:/ / www.perpusnas.go.id/lawdetail.php?lang=id\&id=170921075004 IoWEqikzlx

Pinasang, B. (2015). Peranan publisistas dalam meningkatkan wisatawan di
Sulawesi Utara. Jurnal Acta Diurna, 4(4), 1-7. Retrieved from https:/ / ejournal.unsrat.ac.id/index.p $\mathrm{hp} /$ actadiurna/article/view/8501/80 76

Rahadian, G., Rohanda, \& Anwar, R. K. (2014). Peranan perpustakaan sekolah dalam meningkatkan budaya gemar membaca. Kajian Informasi $\mathcal{E}$ Perpustakaan, 2(1), 27-36. https://doi.org/https://doi.org/10.2 4198/jkip.v2i1.11628.g5453

Rastati, R. (2008). Penggunaan warna dalam kebudayaan (Skripsi). Universitas Indonesia, Depok, Depok. Retrieved from

http:/ /lib.ui.ac.id/file?file=digital/12 6837-RB08R39p-Penggunaan warnaPendahuluan.pdf

Ridgway, J., \& Myers, B. (2014). A study on brand personality: consumers' perceptions of colours used in fashion brand logos. International Journal of Fashion Design, Technology and Education, $\quad 7(1), \quad 50-57$. https://doi.org/https:/ / doi.org/10.1 080/17543266.2013.877987

Rustan, S. (2011). Huruf font tipologi. Jakarta: Gramedia Pustaka Utama.

Setiawan, H. (2015). Analisis semiotik logo NOKIA: Menggunakan metode semiotik Charles Sanders Pierce (Skripsi). Universitas Mercu Buana, Jakarta.

Usman, N. H. (2017). Representasi nilai toleransi antarumat beragama dalam film "Aisyah Biarkan Kami Bersaudara" (Skripsi). UIN Alauddin Makasar. Retrieved from http://repositori.uinalauddin.ac.id/8433/1/Nur Hikma Usman.pdf

Wang, Z., Duff, B. R. L., \& Clayton, R. B. (2017). Establishing a factor model for aesthetic preference for visual complexity of brand logo. Journal of Current Issues $\mathcal{E}$ Research in 
Advertising, 39(1), 83-100.

https://doi.org/https://doi.org/10.1

080/10641734.2017.1372325

Wood, D. (2017). A Semiotic Rosetta Stone:

language of pragmatic semiotics. The

Design Journal, 20(1), S28-S37.

https://doi.org/https://doi.org/10.1

Developing a designercentric meta-

080/14606925.2017.1353006 